\title{
Electrical and Dielectric Characterization of $\mathrm{Na}_{0.5} \mathrm{Li}_{0.5} \mathrm{Zr}_{2}\left(\mathrm{PO}_{4}\right)_{3}$
}

\author{
Umaru Ahmadu', Tomas Salkus ${ }^{2}$, Abubakar Ohinoyi Musa ${ }^{3}$, Kasim Uthman Isah ${ }^{1}$ \\ ${ }^{1}$ Department of Physics, Federal University of Technology, Minna, Nigeria. \\ ${ }^{2}$ Faculty of Physics, Vilnius University, Vilnius, Lithuania. \\ ${ }^{3}$ Department of Physics, Bayero University, Kano, Nigeria. \\ E-mail: u.ahmadu@hotmail.com \\ Received July 11, 2011; revised September 15, 2011; accepted October 16, 2011
}

\begin{abstract}
$\mathrm{Na}_{0.5} \mathrm{Li}_{0.5} \mathrm{Zr}_{2}\left(\mathrm{PO}_{4}\right)_{3}$ has been synthesized by solid state reaction and characterized by thermogravimetry/ differential thermal analyses (TGA/DTA) in the temperature range $300-1573 \mathrm{~K}$. X-ray diffraction measurements have been carried out to determine the phase of the composition and scanning electron microscopy (SEM) for microstructure evaluation. Impedance spectroscopy at different temperatures $(310-600 \mathrm{~K})$ and frequencies $(300 \mathrm{kHz}-1 \mathrm{GHz})$ have been carried out and the dielectric relaxation behaviour was determined under the same conditions. A dc conductivity maximum value of $0.25 \mathrm{~S} / \mathrm{m}$ at $580 \mathrm{~K}$ was observed. However, the mixed alkali effect was not observed. The material exhibited relaxation behaviour with a peak in the dielectric permitivity $\varepsilon^{\prime}$ at $469 \mathrm{~K}$. There were no structural transformations observed.
\end{abstract}

Keywords: NZP, Impedance Spectroscopy, Dielectric Relaxation, Electrical Conductivity

\section{Introduction}

At present one of the most important materials under investigation belongs to the NZP (sodium zirconium phosphate) family of compounds with formula $\mathrm{NaZr}_{2}$ $\left(\mathrm{PO}_{4}\right)_{3}$. NZP has many potential applications, which includes, environmental gas sensors (for detection of pollutant gases like $\mathrm{CO}_{2}$ ), thermal expansion [1], nuclear waste immobilization [2,3] and rechargeable lithium ion batteries. The $\mathrm{Na}, \mathrm{Zr}$, and $\mathrm{P}$ can be substitutted by atoms of different sizes and oxidation states resulting in compounds of different physical and chemical properties, while at the same time retaining the same crystal structure. Such substitutions have lead to an enhancement of electrical conductivity [4,5], among other physical properties. The compound has been synthesized mainly using the solid state reaction method and $\mathrm{ZrO}_{2}$ is usually precipitated [6] due to the high temperature required for the synthesis. Additionally, small impurity phases $\left(\mathrm{Li}_{3}\right.$ $\mathrm{PO}_{4}, \mathrm{LiTiPO}_{4}, \mathrm{ZrP}_{2} \mathrm{O}_{7}$ ), among others, have been detected that do not affect the overall conductivity of the compositions [7-9].

The composition $\mathrm{Na}_{1-\mathrm{x}} \mathrm{Li}_{\mathrm{x}} \mathrm{Zr}_{2}\left(\mathrm{PO}_{4}\right)_{3}$, (where $\mathrm{x}=0.0$, $0.3,0.5,0.7$ and 1.0) have been studied by Pet'kov et al. [10], by using solid state reaction and characterized by
X-ray diffraction and differential thermal analyses (DTA). Similarly, Naik et al. [11,12] have synthesized $\mathrm{NaZr}_{2}$ $\left(\mathrm{PO}_{4}\right)_{3}$ using microwave techniques at lower temperatures and carried out structural characterizations using XRD. However, the conductivity of $\mathrm{NaZr}_{2}\left(\mathrm{PO}_{4}\right)_{3}$ has been reported to be very low, below the applicable range [13]. A key factor in the application of ionic materials in rechargeable batteries is that they must have high conductivity, of the order $10^{1}$ to $10^{-1} \mathrm{~S} / \mathrm{m}[14]$ in operating conditions. Thus studies on partial as well as full substitutions (of $\mathrm{Na}, \mathrm{Zr}$ and $\mathrm{P}$ ) have been carried out in order to improve the conductivities of the compositions. Moreover, most of the impedance spectoscopy (IS) studies of the compositions have been undertaken within the $\mathrm{kHz}-$ MHz range of frequencies $[6,15]$, wheareas very few studies have been reported in the $\mathrm{GHz}$ range $[5,16]$. There are also no reports on their dielectric relaxation properties.

It is important to know the structure of NZP in order to understand how substitutions of $\mathrm{Na}^{+}, \mathrm{Zr}^{4+}$ or $\mathrm{P}^{5+}$ cations influence the conductivity. NZP has a hexagonal crystal structure and belongs to the rhombohedral symmetry (space group $R \overline{3} c$ ). The structure is made up of $\mathrm{ZrO}_{6}$ octahedra and $\mathrm{PO}_{4}$ tetrahedara which share all their vertices to form interconnected network of channels. $\mathrm{Na}^{+}$ 
ions are located in these channels and can occupy two distinct sites, labelled type I (M1) and type II (M2). In $\mathrm{NZP}$, only the M1 sites are filled and the M2 sites are empty. In order to correlate electrical parameters, such as electrical conductivity and associated activation energies with structural factors, the effect of the size of the bottleneck that connects M1-M2 sites are very important. A representation of the structure and its detailed description has been provided by several authors $[7,18,19]$.

It has been observed that when $\mathrm{Li}^{+}$cations are in these channnels they become suitable candidates for lithium rechargeable cells, if their conductivity at room temperature can be enhanced. We hypothesize that partial substitution of $\mathrm{Na}^{+}$by $\mathrm{Li}^{+}$ions in a 50:50 ratio at these sites should affect the conductivity positively due to their differencies in radii, mass and mobility and it should result in low activation energy. The phenomenon of "mixed alkali effect" has been suspected [7] to be responsible for the low conductivity and high activation energy observed in a similar system (that is, when compared with compounds without $\mathrm{Li}^{+}$ions) in which the authors suggested that further work is needed to arrive at a conclusive position.

In the present work we have carried out the synthesis of $\mathrm{Na}_{0.5} \mathrm{Li}_{0.5} \mathrm{Zr}_{2}\left(\mathrm{PO}_{4}\right)_{3}$ using solid state reaction by sintering at $1523 \mathrm{~K}$. TGA/DTA have been carried out on their powder mixtures $\left(\mathrm{Na}_{2} \mathrm{CO}_{3} \cdot \mathrm{H}_{2} \mathrm{O}, \mathrm{NH}_{4} \mathrm{H}_{2} \mathrm{PO}_{4}, \mathrm{Li}_{2} \mathrm{CO}_{3}\right.$ and $\mathrm{ZrO}_{2}$ ) from room temperature to $1273 \mathrm{~K}$, in order to determine the decomposition and mass losses (temperature stabilty) and phase transformations. In addition, IS and dielectric relaxation relaxation behaviour of the compound have been investigated in the temperature range $310-600 \mathrm{~K}$ and frequency range $300 \mathrm{kHz}-1 \mathrm{GHz}$. A high dc conductivity value was observed and the system exhibited dielectric behaviour at certain frequencies.

\section{Experimental Procedure}

$\mathrm{Na}_{2} \mathrm{CO}_{3} \cdot \mathrm{H}_{2} \mathrm{O}, \mathrm{ZrO}_{2}, \mathrm{Li}_{2} \mathrm{CO}_{3}$ and $\mathrm{NH}_{4} \mathrm{H}_{2} \mathrm{PO}_{4}$ of analytical grade and purity $>99 \%$ were used as starting materials. Stoichiometric amounts of these materials were mixed and thoroughly ground (manually) in an agate mortar for about five hours. The samples were then dried in air for about four hours. Acetone was added in appropriate quantity to homogenize the mixture. Pellets of discs (which were dry) of $13 \mathrm{~mm}$ diameter and $6 \mathrm{~mm}$ thickness were pressed under pressure of $7.42 \cdot 10^{6} \mathrm{~N} / \mathrm{m}^{2}$ for sintering. All the samples were placed inside a gas-heated furnace for eight hours at successive temperatures 573, 773, 1323, 1373, 1423, 1473 and $1523 \mathrm{~K}$, respectively. Between each temperature the samples were allowed to furnacecool to room temperature and then thoroughly re-ground, re-mixed, pelletized and placed back into the furnace for the next round of heating. The first two temperatures were to allow for the volatilization of bye-products, ammonia, water and carbon dioxide. The other temperatures were to allow for full sintering at a maximum temperature of $1523 \mathrm{~K}$.

Powder specimens were used for the measurement of thermal analyses on DTA machine Netzsch DTA404PC in air. The readings were conducted between room temperature and $1273 \mathrm{~K}$ at heating rate of $20.0 \mathrm{~K} / \mathrm{min}$. Similarly, TGA was performed on specimen powders under similar conditions on TGA Pyris 6 (Perkin Elmer, USA) thermal analyser. Both DTA and TGA data were automatically acquired from the machines.

$\mathrm{X}$-ray powder diffraction measurements were carried out using a precision mini X-ray diffractometer MD-10, Version 2.0 .4 by Radicon Ltd. The $2 \theta$ range was $16^{\circ}-70^{\circ}$ and the working power was $25 \mathrm{kV}$ using 20 minutes acquisition time and $\mathrm{CuK} \alpha$ radiation $\lambda=1.5406 \AA$. The scanning step was $0.05^{\circ}$. The surfaces of sintered sample were analysed by SEM working at $5 \mathrm{kV}$. For the electrical measurements, sample was prepared $6.16 \mathrm{~mm}^{2}$ (electrode surface area) and length $1.5 \mathrm{~mm}$. A homemade coaxia line has been used to measure impedance spectra [20]. The control and acquisition of data were carried out using MathLab software, on an Agilent Network Analyser E5062A in the frequency range from 300 $\mathrm{kHz}$ to $1 \mathrm{GHz}$ (at 16 points per decade of frequency) and temperature range 310 - $600 \mathrm{~K}$. Measurements were performed every $10 \mathrm{~K}$ on heating the sample at $1 \mathrm{~K}$ per min using a voltage of $200 \mathrm{mV}$.

\section{Results and Discussion}

The XRD pattern for the composition $\mathrm{Na}_{0.5} \mathrm{Li}_{0.5} \mathrm{Zr}_{2}\left(\mathrm{PO}_{4}\right)_{3}$ shows minor phase $\mathrm{Na}_{5} \mathrm{Zr}\left(\mathrm{PO}_{4}\right)_{3}$ with $\mathrm{ZrO}_{2}$ detected. $\mathrm{Na}_{5}$ $\mathrm{Zr}\left(\mathrm{PO}_{4}\right)_{3}$ has been synthesized and characterized by some workers [21] who reported that it has no specific thermal effects (for example, phase transformation), though, it undergoes reversible phase transitions and decomposes at $433 \mathrm{~K}$ [21]. We thus assume that there is minimal distortion to the crystal lattice and thus shows that the synthesized composition is single phase. Impurity phases have been reported in solid state reactions. Some authors [18] have observed a distortion to the hexagonal lattice (in the preparation of NASICON-based compounds) as a result of presence of some impurity phases $\left(\mathrm{AlPO}_{4}, \mathrm{GeO}_{2}\right)$ which have been found to be a function of either decreasing temperature or of multiple substitutions at specific lattice sites. The authors assumed the effect of these impurities to be negligble on the overall crystal structure. The compound under investigation $\left(\mathrm{Na}_{0.5} \mathrm{Li}_{0.5} \mathrm{Zr}_{2}\left(\mathrm{PO}_{4}\right)_{3}\right)$ was also indexed based on the hexagonal lattice structure and found to belong to the rhombohedral crystal sym- 
metry [10]. The lattice paramters obtained by least-square fitting of the XRD data were $\mathrm{a}=8.7450 \AA$ and $\mathrm{c}=23.2578$ $\AA$. The results of the lattice parameters obtained by some workers [10] for the same composition are $\mathrm{a}=8.7630 \AA$ and $\mathrm{c}=23.4590 \AA$. The value of the experimental density obtained by measuring the dimensions of the pellets is $90 \%$ of the theoeretical density. This shows that it is relatively dense material. The peaks of $\mathrm{Na}_{0.5} \mathrm{Li}_{0.5} \mathrm{Zr}_{2}\left(\mathrm{PO}_{4}\right)_{3}$ are found to correspond to the standard ICDD, PDF-2 (33-1312) pattern, except for the detected phases, and could be identified with $\mathrm{Na}_{0.5} \mathrm{Li}_{0.5} \mathrm{Zr}_{2}\left(\mathrm{PO}_{4}\right)_{3}$. Complete synthesis of the composition was therefore achieved by sintering at $1523 \mathrm{~K}$ by heating for $8 \mathrm{~h}$, although the synthesis of the main compound $\left(\mathrm{NaZr}_{2}\left(\mathrm{PO}_{4}\right)_{3}\right)$ has been reported [11] using microwave heating at $923 \mathrm{~K}$ for $1 \mathrm{~h}$. Peak broadening was observed in the XRD diffraction peaks as a result of crystallite size due to microstrain (caused by the high temperature used) [22]. High temperature sintering is normally used in the preparation of NZP compositions which results in microcraking as a result of the microstrain it induces in the ceramic on cooling [9]. Figure 1 depicts SEM micrograph of the surfaces of $\mathrm{Na}_{0.5} \mathrm{Li}_{0.5} \mathrm{Zr}_{2}\left(\mathrm{PO}_{4}\right)_{3}$ ceramics showing large grains $(3-7 \mu \mathrm{m})$ and very small porosity. The grains are well-structured and have different sizes.

The thermal analyses results were obtained for TGADTA of the composition in the temperature range 310$1273 \mathrm{~K}$. There is overall mass loss of $23 \%$ in the TGA. The composition is stable and the thermal stability temperature starts from $600 \mathrm{~K}$ and is an indication of the completion of the formation of the product phase. The steps in decomposition represent the evolution of water, amonia and carbondioxide. Similar results were obtained by some

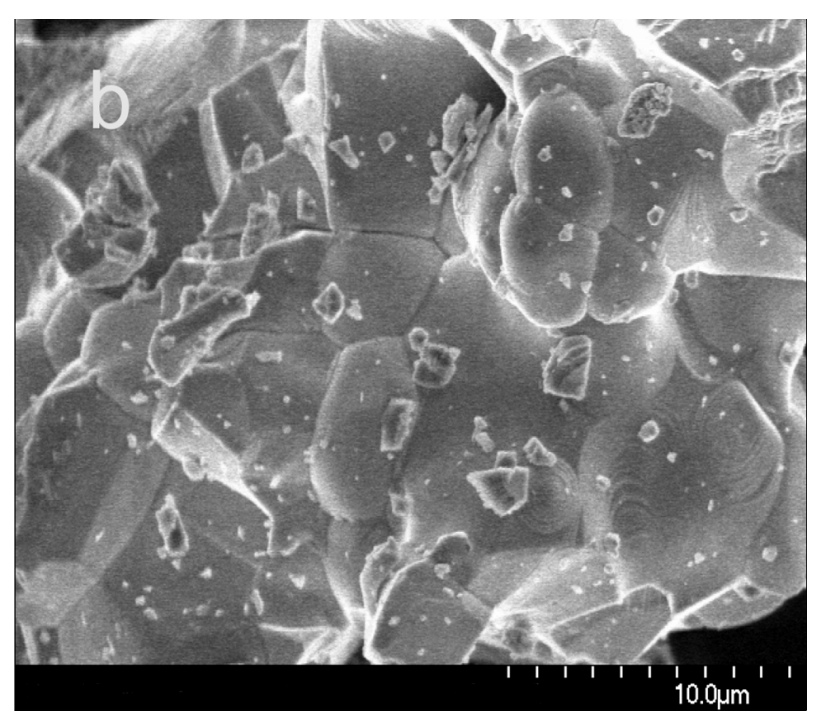

Figure 1. Micrograph of sintered $\mathrm{Na}_{0.5} \mathrm{Li}_{0.5} \mathrm{Zr}_{2}\left(\mathrm{PO}_{4}\right)_{3}$ showing surfaces of well-structured grains of different sizes. workers [11] in which they reported that the thermal stability temperature is around $923 \mathrm{~K}$, though the steps in decomposition differed as a result of the starting materials used and the subsequent chemical routes of the reaction. The DTA results shows only one sharp exothermic peak at $469 \mathrm{~K}$, which is attributted to loss of water of hydration. Similarly, the above authors [11] had differing number of peaks, due to the different chemicals used and the routes in the reactions. However, there is no report of any structural transformations or thermal effects (which may affect electrical conductivity and activation energy for conduction, among others) found in this work in the temperature range investigated. Other workers [21] have similarly reported the absence of any thermal effects in $\mathrm{NaZr}_{2}\left(\mathrm{PO}_{4}\right)_{3}$, in the temperature range $298-1123 \mathrm{~K}$. The detailed thermal analyses of the composition has been reported elsewhere [23]. The importance of the thermal analyses is to establish the thermal stability range of the compound and to find out whether there was any phase transition.

Figure 2 shows the variation of the imaginary $\left(z^{\prime \prime}\right)$ versus real $\left(z^{\prime}\right)$ parts of impedance at different temperatures $310-600 \mathrm{~K}$. All the plots show an increasing reduction in the radii of the partially formed semicircles and shrink towards the origin. This implies an increase in conductivity as a result of reduction in resistance of the sample. At low temperatures $(310-350 \mathrm{~K})$ and frequencies, the overlap of the partially formed arcs due to grains (bulk) and grain boundary are visible. At higher tempe ratures the grain boundary component becomes more visible and

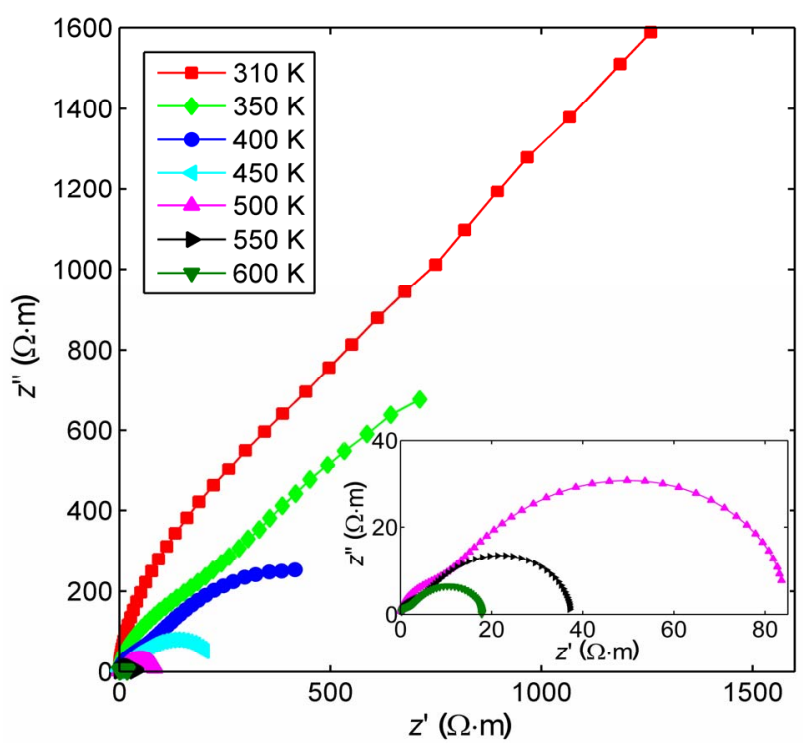

Figure 2. Imaginary $\left(z^{\prime \prime}\right)$ versus real $\left(z^{\prime}\right)$ impedance plots at different temperatures $(310-600 \mathrm{~K})$ and frequencies $(300 \mathrm{kHz}-1 \mathrm{GHz})$ of $\mathrm{Na}_{0.5} \mathrm{Li}_{0.5} \mathrm{Zr}_{2}\left(\mathrm{PO}_{4}\right)_{3}$, Inset, shows exploded plots for temperatures $500-600 \mathrm{~K}$. 
the arcs become more distinct. The overlap can be attributted to closeness of their relaxation frequencies and to inhomogeneities that may be present in the composition. The persistence of the grain boundary component up to the maximum temperature may be attributted to the temperature range investigated. The impedance curves at high temperatures $(500-600 \mathrm{~K})$ have been exploded due to their low impedance values in order to elucidate the features more clearly, as shown in the inset of Figure 2, where the curves are seen to make greater curvatures, and the grain and grain boundary contributions become visible. The grain boundary contribution is apparently dominant and shows more curvature at this temperatures compared to the bulk. The electrode effects do not seem to be significant and thus did not show up even though blocking electrodes were used (platinum).

Figure 3(a) shows the variation of the imaginary part of impedance $\left(z^{\prime \prime}\right)$ versus frequency at different temperatures $(310-600 \mathrm{~K})$ in the frequency range $300 \mathrm{kHz}$ $1 \mathrm{GHz}$. Two relaxation processes can be observed: the one at higher frequencies is attributed to ionic relaxation in the bulk, while the other ( lower frequency) is attributed to ionic relaxation in grain boundaries, as indicated in Figure 3(a). All the curves show a systematic fall in the maximum values of the peak of $z^{\prime \prime}$ as the temperature increases. Both peaks shift toward higher frequencies with increase in temperature, indicative of the presence of relaxation. The dominance and sharpness of the grain boundary is obvious. Based on an Arrhenius-type relation, the relaxation frequencies $\left(f_{b}\right)$ associated with each peak (for bulk contribution) can be related to the bulk and used to determine the corresponding activation energy for relaxation in the bulk $\left(E_{f b}\right)$ from the equation:

$$
f_{b}=f_{o} \mathrm{e}^{\frac{-E_{f b}}{K T}}
$$

where $f_{o}$ is the preexponential factor and $\mathrm{k}$ and $\mathrm{T}$ represent the Boltzmann constant and temperature, respectively. The relaxation time $\tau_{b}$ can be derived from the reciprocal of the relaxation frequency $\omega_{b}$ (where $\omega_{b}=2 \pi f_{b}$ ) and $\omega$ is the angular frequency. It can be seen from Figure 3(b) that a linear relation can be deduced from the above equation when $\ln f_{b}$ versus $1000 / \mathrm{T}$ graph is plotted in the temperature range 400 $600 \mathrm{~K}$. A linear fit to the above equation yielded bulk activation energy for relaxation of $0.36 \mathrm{eV}$. A similar approach has been reported in the study of $\mathrm{Na}_{1+\mathrm{x}} \mathrm{Ti}_{2-\mathrm{x}}$ $\mathrm{Al}_{\mathrm{x}}\left(\mathrm{PO}_{4}\right)_{3}$, where $\mathrm{x}=0.6-0.9$ [7], in which the frequency at which the maxima of the imaginary part of modulus $\left(m^{\prime \prime}\right)$ peaks occurs $\left(f_{\max }\right)$ was used to calculate the activation energy. This approach has been justified on the grounds that the modulus is not affected by the grain boundary contributions, since the peak frequency scales as the bulk conductivity over the bulk permitivity $(\sigma / \varepsilon)$.
Additionally, when the bulk capacitance is temperatureindependent, $f_{\max }$ is equally activated as the conductivity. Figure 3(c) shows the Arrhenius representation of

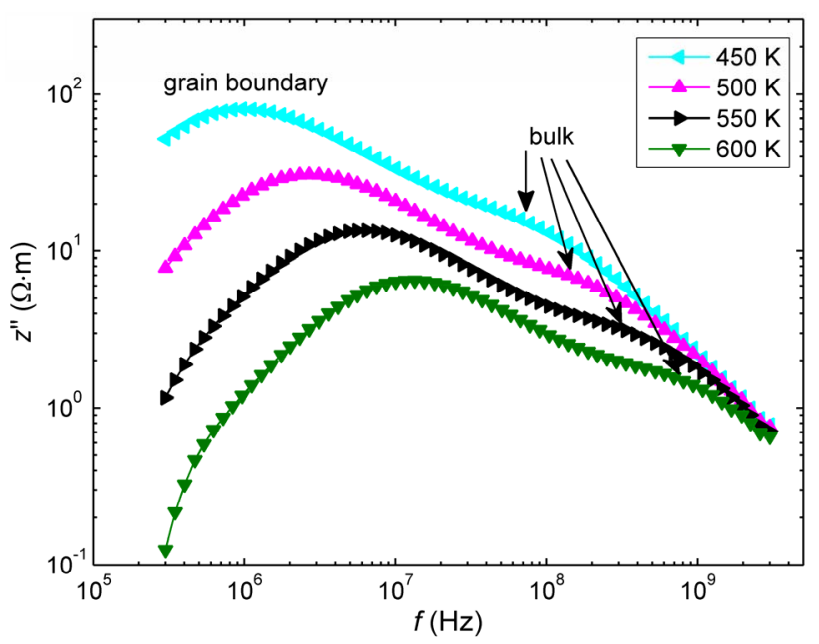

(a)

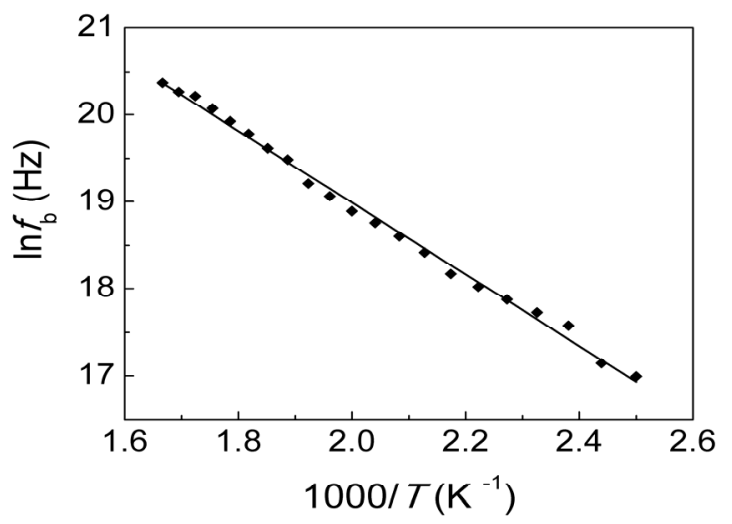

(b)

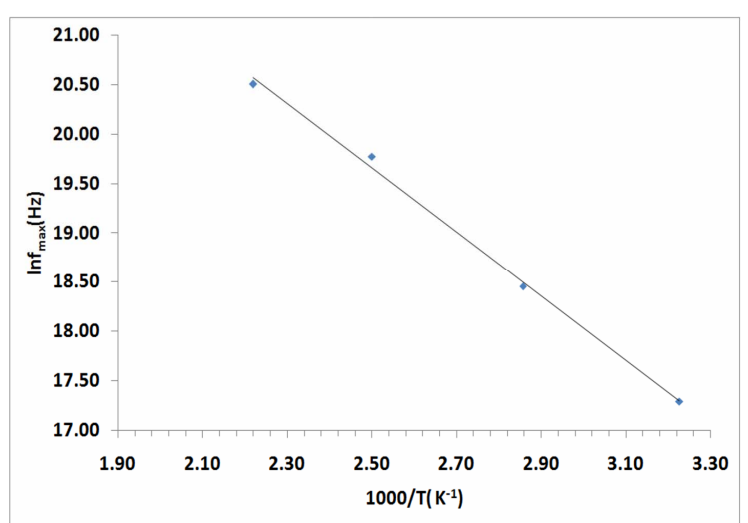

(c)

Figure 3. (a) $z^{\prime \prime}$ versus frequency plot at 450 - $600 \mathrm{~K}$ for $\mathrm{Na}_{0.5} \mathrm{Li}_{0.5} \mathrm{Zr}_{2}\left(\mathrm{PO}_{4}\right)_{3}$; (b) Arrhenius plot of $\ln f_{b}$ against 1000/T for $\mathrm{Na}_{0.5} \mathrm{Li}_{0.5} \mathrm{Zr}_{2}\left(\mathrm{PO}_{4}\right)_{3}$; (c) Arrhenius plot of In $f_{\text {max }}$ against 1000/T for $\mathrm{Na}_{0.5} \mathrm{Li}_{0.5} \mathrm{Zr}_{2}\left(\mathrm{PO}_{4}\right)_{3}$. 
$\ln f_{\max }$ against $1000 /$ T plot. $E_{f \max }(0.28 \mathrm{eV})$ is close to that for bulk $\left(E_{f b} \sim 0.36 \mathrm{eV}\right)$. The corresponding activation energy for the grain boundary $\left(E_{f g b}\right)$, obtained from the slope (not shown) of the linear fit to the Arrhenius equation for relaxation frequency $\left(E_{f g b}\right)$ is $\sim 0.38$ $\mathrm{eV}$, which is similar to $E_{f b}$.

The variation of the real part of ac conductivity $\sigma^{\prime}\left(\sigma_{a c}\right)$ with frequency has also been studied at different temperatures $(310-600 \mathrm{~K})$ and is shown in Figure 4(a). Two regions are visible, the frequency independent region (plateau), associated with dc conductivity at low frequencies (related to the long range transport of $\mathrm{Li}^{+}$and $\mathrm{Na}^{+}$ions), and the high frequency dispersive region, which is attributted to the short range hopping motion of the ions as the temperature increases. At lower temperatures some of the curves do not obey the Jonscher power law completely since only the high frequency dispersive regions are visible. The dc or low frequency range becomes narrower and eventually disappears as the temperature decreases, leaving only the high frequency dispersive region. The maximum value of the $\sigma^{\prime}$ obtained in this work is $\sim 0.32 \mathrm{~S} / \mathrm{m}$ at $600 \mathrm{~K}$.

Figure 4(b) is a log-log plot of the ac conductivity versus frequency in the temperature range $310-600 \mathrm{~K}$. It is known that the ac conductivity of ionic materials at a given temperature is usually described by the power law equation, expressed as:

$$
\sigma_{a c}=\sigma_{d c}+A \omega^{n},
$$

where, $\sigma_{d c}$ is the extrapolated dc conductivity value of the frequency independent region which shows a flat response at low frequencies, $A$ is the ac coefficient which is temperature-dependent and $\mathrm{n}$ is the correllation exponent of the mobile ions. At higher frequencies the conductivity shows dispersion. This equation has been applied in identifying the common qualitative features of many disordered solids, such as glasses, structurally disordered crystals, and supercooled melts [24,25]. In Figure 4(b), the crossover point of the frequency-independent plateau and the high frequency ac dispersive region shifts towards high frequencies with increasing temperature. This is explained by the fact that with increase in temperature, the kinetic energy of the ions also increases and hence their vibrational frequency. Analyses of the plots shows that the onset part of the conductivity dispersion at different temperatures lie on a straight line. This implies that $\sigma_{d c}(\mathrm{~T})$ and the onset frequency $A f(T)$ are proprtional to eachother, and that both are thermally activated with almost the same energy of activation, indicating a general feature of the power law proposed by Jonscher [18]. The frequency-independent region (flat response ) increases with temperature and all the plots obey the Jonscher's law at all temperatures.
We can determine, from the slope of the $\ln \sigma_{a c}$ vs $\ln$ $f$ plot, the value of the correlation exponent $\mathrm{n}$. Our result shows that the value decreases with increase in temperature in a narrow range $(0.26-0.36)$ and shows that $\mathrm{n}$ is a temperature-dependent relaxation process. The plot of $\mathrm{n}$ versus $\mathrm{T}$ at different temperatures is shown in Figure 4(c) with the straight line fit to the relation and shows an increase of $n$ with decrease of temperature. However, the values of $\mathrm{n}$ reported by some authors [7] in their study is $\sim 0.60$, for all the compostions. Others [18] however, reported values in the range $\sim 0.61-0.63$ in the study of $\mathrm{Li}_{1+\mathrm{x}}\left[\left(\mathrm{Ta}_{1-\mathrm{x}} \mathrm{Ge}_{\mathrm{x}}\right) \mathrm{Al}\right]\left(\mathrm{PO}_{4}\right)_{3}$, where $\mathrm{x}=0.0-1.0$, in some compositions, and up to 0.90 in others. The authors could find no explanation for the high values in the other compositions and suggested further investigations. Our present result is comparatively lower and points to a need for further investigations too. The electrical conduction mechanism of ionic materials has been determined by the

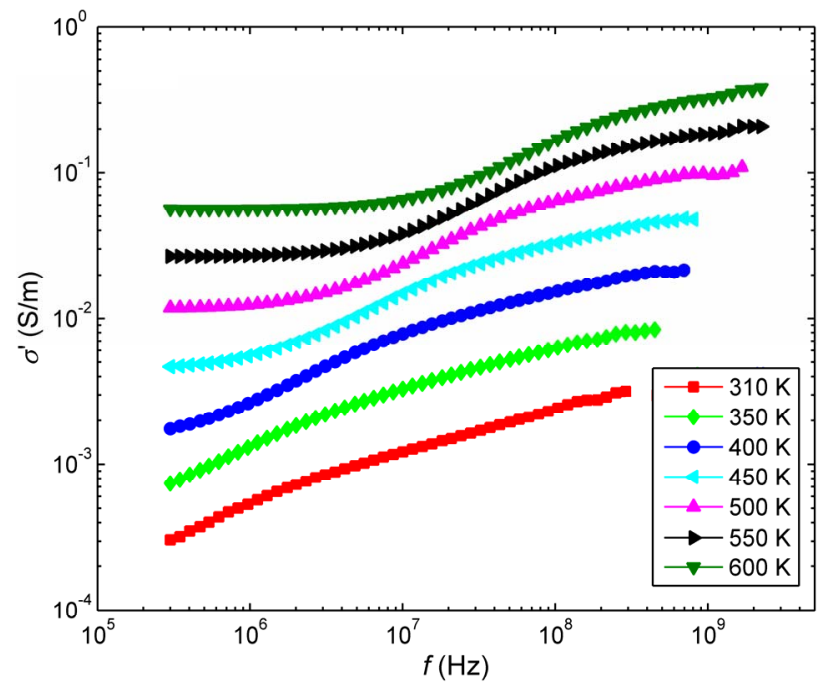

(a)

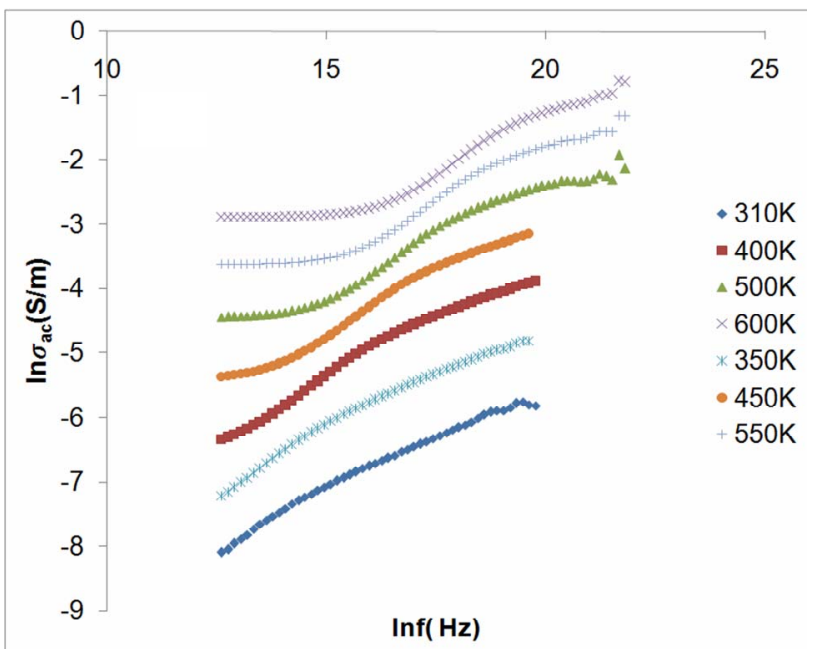

(b) 


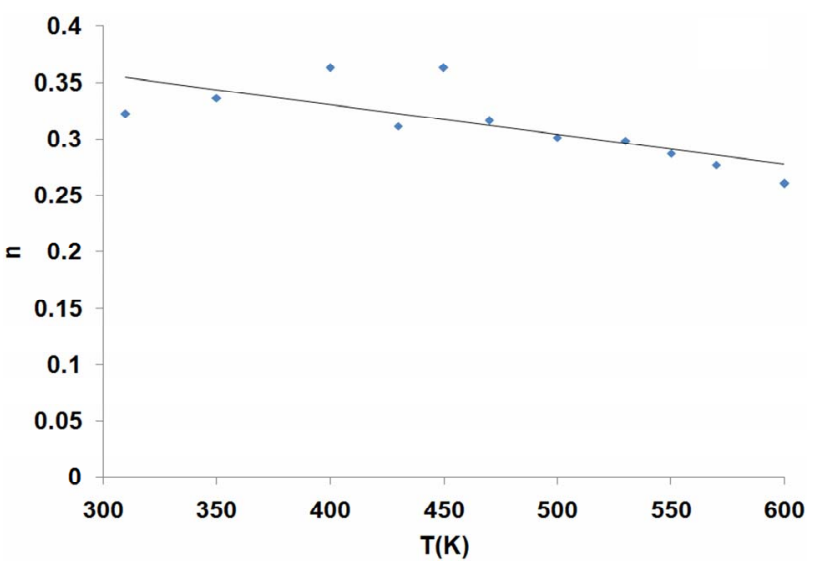

(c)

Figure 4. (a) Frequency depences of real part of complex conductivity of $\mathrm{Na}_{0.5} \mathbf{L i}_{0.5} \mathrm{Zr}_{2}\left(\mathbf{P O}_{4}\right)_{3}$; (b) Plot of $\ln \sigma_{\mathrm{ac}}$ vs $\ln \mathbf{f}$ at different temperatures; (c) Plot of correllation exponent $n$ versus temperature.

temperaure behaviour of the value of $n$ based on the application of various models [26] that have been proposed. These include quantum mechanical tunnelling model (QMT), the overlapping large polaron model (OL$\mathrm{PT})$ and the correlated barrier hopping model $(\mathrm{CBH})$. It seems plausible to use the $\mathrm{CBH}$ model where charge carriers hop between sites separating them and predicts a decrease in the value of $\mathrm{n}$ with increase in temperature [27], since this is the case observed in our data.

Figure 5 is the Arrhenius plot of $\ln \sigma_{b}, \ln \sigma_{t}$ against $1000 / \mathrm{T}$ deduced from the impedance curves. Bulk conductivity $\sigma_{b}$ was deduced by extrapolation of the semicircle to the real $z^{\prime}$ axis to obtain the resistance. The slope of the plot gives the activation energy for the dc conduction $E_{b}$ in the bulk as $\sim 0.33 \mathrm{eV}$, whereas the activation energy for total conductivity $E_{t}$ is $\sim 0.37 \mathrm{eV}$ and $\sigma_{t} \sim 0.06 \mathrm{~S} / \mathrm{m}$ at $600 \mathrm{~K}$. Other workers [6] obtained a value of $E_{t} \sim 1.34 \mathrm{eV}$ and conductivity $\sigma_{t} \sim 0.09$ $\mathrm{S} / \mathrm{m}$ at $650 \mathrm{~K}$, which is comparable with our result since it is was obtained at a lower temperature. $E_{b}$ has a value in close agreement with that for relaxation of $m^{\prime \prime}\left(E_{\text {fmax }} \sim\right.$ $0.28 \mathrm{eV})$ and for $E_{f b}(\sim 0.36 \mathrm{eV})$, which indicates that the conduction mechanism can be attributted to the classical hopping model and the charge carriers have to overcome the same energy barrier [28]. The maximum dc conductivity attained in the bulk is $\sim 0.25 \mathrm{~S} / \mathrm{m}$ at the maximum temperature of $580 \mathrm{~K}$ and $0.01 \mathrm{~S} / \mathrm{m}$ at $400 \mathrm{~K}$. On the other hand, the room temperature value of $\sigma_{b}$ r $0.01 \mathrm{~S} / \mathrm{m}(370 \mathrm{~K})$. This is comparable to the reported [18] maximum values of $\sigma_{b} \sim 0.05 \mathrm{~S} / \mathrm{m} \quad(393 \mathrm{~K})$ with $E_{b} \sim 0.45 \mathrm{eV}$, while others [4,7] reported a maximum $\sigma_{b}$ of $4.11 \cdot 10^{-6} \mathrm{~S} / \mathrm{m}(423 \mathrm{~K})$ at $E_{b} \sim 0.77 \mathrm{eV}$ and $\mathrm{S} / \mathrm{m}$ $(400 \mathrm{~K})$ at $E_{b} \sim 0.66 \mathrm{eV}$, respectively, for various
NASICON compositions. This shows that the activation energy for conductivity obtained in our work is much lower and hence the high value of conductivity (which is generally in the range for NASICON) obtained, even though two mobile ions were involved.

We conclude that there was no blocking of the conducting channels by the ions at the specific lattice sites, and that since the ions have the same charge, other factors such as ion size, polarizability and mobility may be responsible for the high conductivity and the low activation energy obtained [29]. This is because $\mathrm{Na}^{+}$ion has larger radius $\left(0.98 \AA\right.$, with polarizability $\left.\alpha=0.255 \AA^{3}\right)$ than lithium ion $\mathrm{Li}^{+}$, hence greater polarizability. When this is combined with the higher mobility of $\mathrm{Li}^{+}$compared to $\mathrm{Na}^{+}$ions, they effectively couple up to bring about the enhancement of the electrical parameters. However, it is acknowledged that to identify and quantify the individual contributions of the ions, more work is needed.

Sinclair and West have suggested the combined usage of impedance and modulus spectroscopic plots to rationalize dielectric properties. It is also now widely used to analyze ionic conductivities [30]. The plot of the frequency dependence of the imaginary part of electric modulus $\left(\mathrm{m}^{\prime \prime}\right)$ at different temperatures is shown in Figure 6. The imaginary part of electric $m^{\prime \prime}$ is indicative of energy loss under electric field. $m^{\prime \prime}$ is seen to rise smoothly to a peak value and subsequently decreases at higher frequencies at all the temperatures. The peaks seem asymmetrical and broader than predicted by the non-ideal Debye behaviour. The low frequency side of the peaks is an indication of the range in which the ions drift to long distances and the position of the peaks is suggestive of the transition from short range to long-range

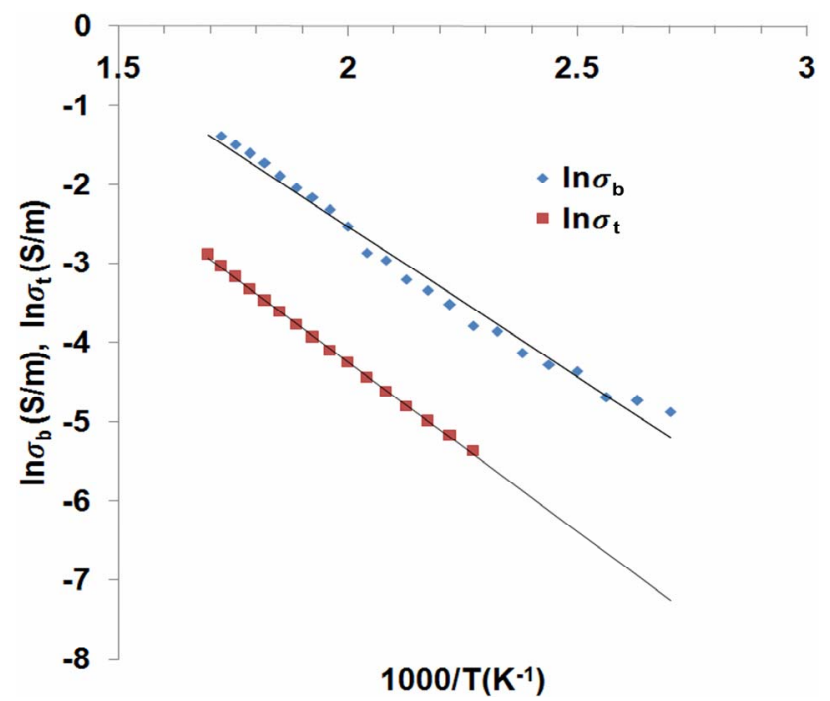

Figure 5. Plot of $\ln \sigma_{b}, \ln \sigma_{t}$ against $1000 / T$ for bulk (dc) and total conductivity of $\mathrm{Na}_{0.5} \mathrm{Li}_{0.5} \mathrm{Zr}_{2}\left(\mathrm{PO}_{4}\right)_{3}$. 


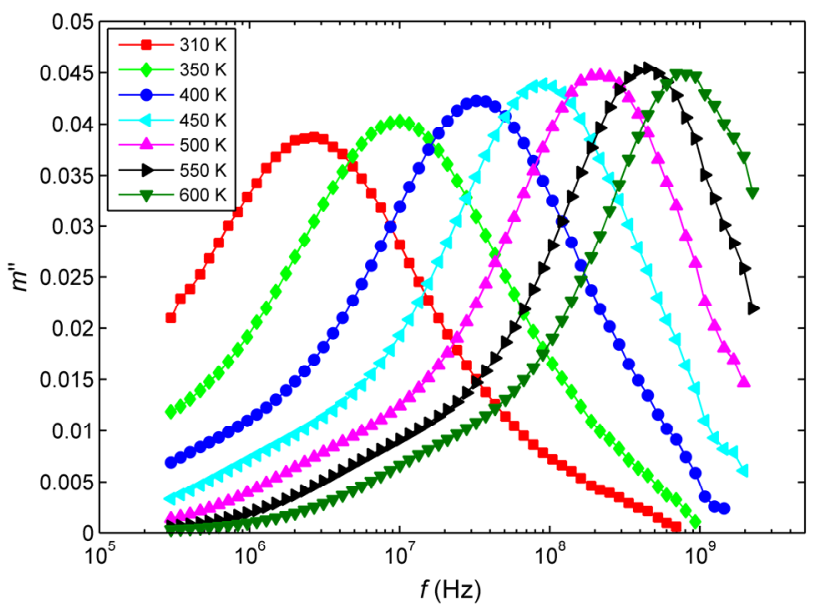

Figure 6. Frequency dependencies of imaginary part of modulus at different temperatures for $\mathrm{Na}_{0.5} \mathrm{Li}_{0.5} \mathrm{Zr}_{2}\left(\mathrm{PO}_{4}\right)_{3}$.

mobility with decreasing frequency (that is performing successful hopping from one site to another neighbouring site). In the frequency range which is above the peak the ions are spatially confined to their potential wells and free to move within the wells. The maxima of the peaks shift to higher frequencies as the temperature increases with an increasing magnitude of the peaks of $\mathrm{m}^{\prime \prime}$. This is an indication that the relaxation is thermally activated process and suggests that the hopping mechanism dominates intrinsically which directly suggests an increase in dielectric permitivity $\varepsilon^{\prime}$. Most of the curves tend to merge towards the lower frequency which may be due to lack of contribution from space charges at high frequencies. The merger at lower frequencies can also be attributted to interfacial polarization which is dominant at low frequencies.

We can further examine the non Debye behaviour of the modulus plots by studying the imaginary part of impedance $\left(z^{\prime \prime}\right)$ and modulus $\left(m^{\prime \prime}\right)$ versus $\log f$ plots obtained at $450 \mathrm{~K}$ (Figure 7) for different temperatures. This clearly indicates departures from the ideal Debye behaviour (the inset of Figure 7 is for the electric modulus at the same temperature). Only one peak is visible in both the $z^{\prime \prime}$ and $m^{\prime \prime}$ frequency dependecies which can be atributted to the bulk, as has been pointed out earlier, as there is no other visible peak, suggesting that the grain boundary contribution is evidently minimal based on the modulus formalism. Similarly, the width of the $z^{\prime}$ versus $\log f$ plot at half height is greater than 1.14 decades of frequency and the peaks of $z^{\prime \prime}$ and $m^{\prime \prime}$ are not coincident, which further suggests a departure from the ideal Debye behaviour (ideal Debye behaviour is 1.14 decades difference in frequency). However, it is observed that the peaks of $z^{\prime \prime}$ and $m^{\prime \prime}$ plots are almost symmetrical and the shifts and changes in the values of $f_{\text {max }}$ at other temperatures suggests a variation in capacitance.

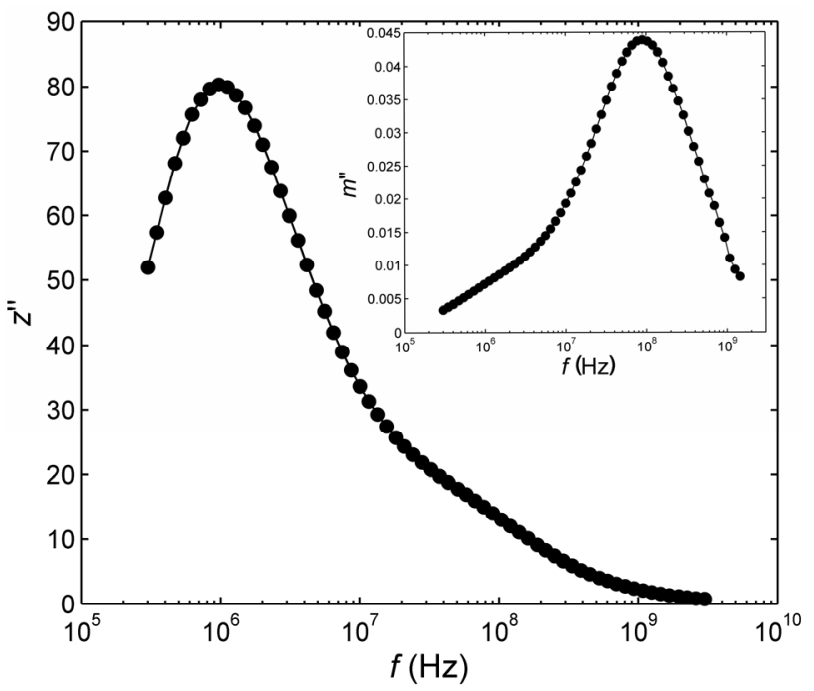

Figure 7. Plot of imaginary part of impedance against $\log f$ at $450 \mathrm{~K}$ for $\mathrm{Na}_{0.5} \mathrm{Li}_{0.5} \mathrm{Zr}_{2}\left(\mathrm{PO}_{4}\right)_{3}$. Inset is the plot of real part of electric modulus versus $\log f$ at the same temperature.

In Figure 8 the plot of real part of electric modulus $\left(m^{\prime}\right)$ versus frequency at different temperatures is shown. The maxima of $m^{\prime}$ falls with increase in temperature in all the plots. At low frequencies and temperatures (310 $600 \mathrm{~K}), m^{\prime}$ tends to lower values confirming that electrode effects make negligible conbribution and may be ignored in the modulus formalism. The effect is also not apparent in the $z^{\prime \prime}$ vs $z^{\prime}$ curves discussed earlier. The $m^{\prime}$ value represents the ability of the material to store energy and increases with increase in temperature at low frequencies. The frequency independent variation of $m^{\prime}$ at high frequencies can be attributted to absence of space charge effects due to inhomogeneities in the compsosition.

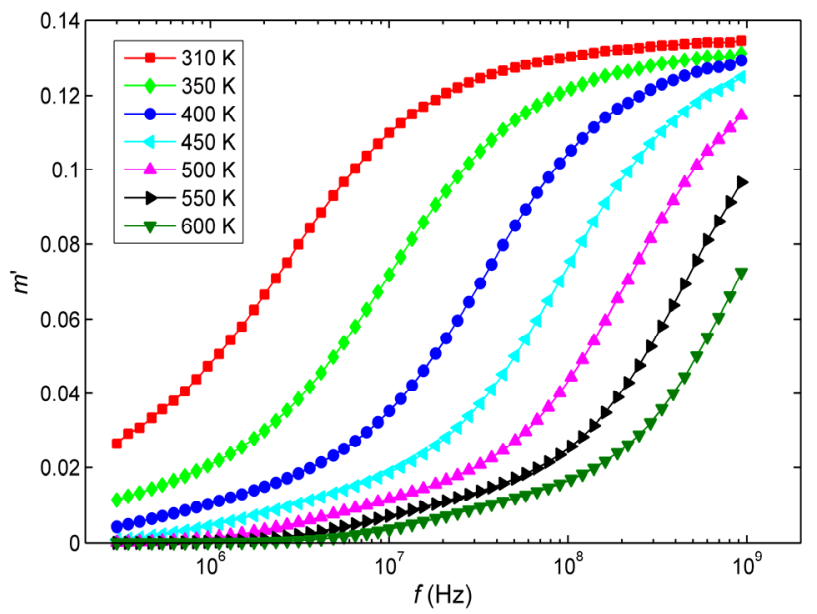

Figure 8. Frequency dependences of real part of electric modulus at different temperatures for $\mathrm{Na}_{0.5} \mathrm{Li}_{0.5} \mathrm{Zr}_{2}\left(\mathrm{PO}_{4}\right)_{3}$. 
In Figure 9(a) the plot of the variation of real part of dielectric permitivity $\varepsilon^{\prime}$ vs frequency in the temperature range $310-600 \mathrm{~K}$ is shown. The dielectric constant response of a system is due to electronic, ionic, dipole and space charge polarizations, among others. The space charge effects are negligible at very low temperatures and noticeable only in the low frequency region. Peaks are observed in the $\varepsilon^{\prime}$ values from $400-600 \mathrm{~K}$ which shift towards higher frequencies with increase in temperature, this is evidence of the presence of relaxation in the system. The dielectric permitivity increases with temperature at low frequencies before it reaches a peak. Peak maxima have been attributted to several factors, among which is feroelectric phase transitions [28] and to the begining of crystallization. The relevant dielectric mechanism could be due to several causes, such as dipole polarization due to the frequency range in which the peak occurs and the fact that the loss factor $\varepsilon^{\prime \prime}$ peaks fall in this range. At all the temperatures under investigation, $\varepsilon^{\prime}$ decreases with increase in frequency above the maxima. The decrease is significant especially at low frequencies, asociated with the presence of mobile $\mathrm{Li}^{+}$and $\mathrm{Na}^{+}$ion polarization. On the otherhand, the increasing value of $\varepsilon^{\prime}$ at low frequencies can result from charge accumulation at the interface, thus the low frequency dispersion of $\varepsilon^{\prime}$ gradually increases with increase in temperature due to an increase in the interfacial polarization, as well as thermal activation associated with the mobile ions. The interfacial polarization is insignificant at high frequencies and hence $\varepsilon^{\prime}$ remains relatively constant [31]. When the temperature rises the dielectric dispersion shifts to higher frequencies. At high frequencies $\varepsilon^{\prime}$ also decreases due to the high frequency of the field which reduces the contribution of the charge carries towards the dielectric permitivity $\varepsilon^{\prime}$ and tends to a static value at all temperatures as a result of absence of space charge effects. In the temperature range $310-400 \mathrm{~K}$, there are no peaks owing to the frequency range investigated. At 550 and $600 \mathrm{~K}$, the peaks are broad and reflect the distribution of relaxtion times in the system.

Figure 9(b) shows the variation of imaginary part of dielectric permitivity $\left(\varepsilon^{\prime \prime}\right)$ as a function of frequency in the temperature range $310-600 \mathrm{~K}$. We observe that $\varepsilon^{\prime \prime}$ decreases with increase in frequency at all the temperatures under study. It has been generally postulated that the contribution to the dielectric loss consists of both the conduction and relaxation components. Thus the imaginary part of dielectric loss has been explained based on the $\sigma_{d c} / w \varepsilon_{o}+\varepsilon_{a c}^{\prime \prime}$, where $\varepsilon_{o}$ is vaccum dielectric constant, $\omega=2 \pi f$ is angular frequency and $\varepsilon_{a c}^{\prime \prime}$ is the dielectric loss due to relaxation process. The higher value of $\varepsilon^{\prime \prime}$ at relatively low frequency may be attributted to the contribution arising from both the conduction and relaxation losses. At higher frequencies however, relaxation losses are the only sources of dielectric loss. We also notice that $\varepsilon^{\prime \prime}$ increases with increase in temeprature because as the relaxation loss component reduces the conduction loss component increases more rapidly [30]. Further, it is seen that at all temperatures $\varepsilon^{\prime \prime}$ values approach a static value close to zero at higher frequencies.

The temperature dependence of $\varepsilon$ ' was also investigated in the temperature range $310-600 \mathrm{~K}$ and frequency range $0.3 \mathrm{MHz}-1 \mathrm{GH}$ (Figure 9(c)). It is observed that at high frequency $(1 \mathrm{GHz})$ the material shows an almost temperature-independent behaviour due to the cessation of interfacial polarization and absence of space charge effects. The capacitance of the bulk is almost independent of temperature and the slight increment seen in $\varepsilon^{\prime}$ is due to ion migration. However, at lower temperatures, all the

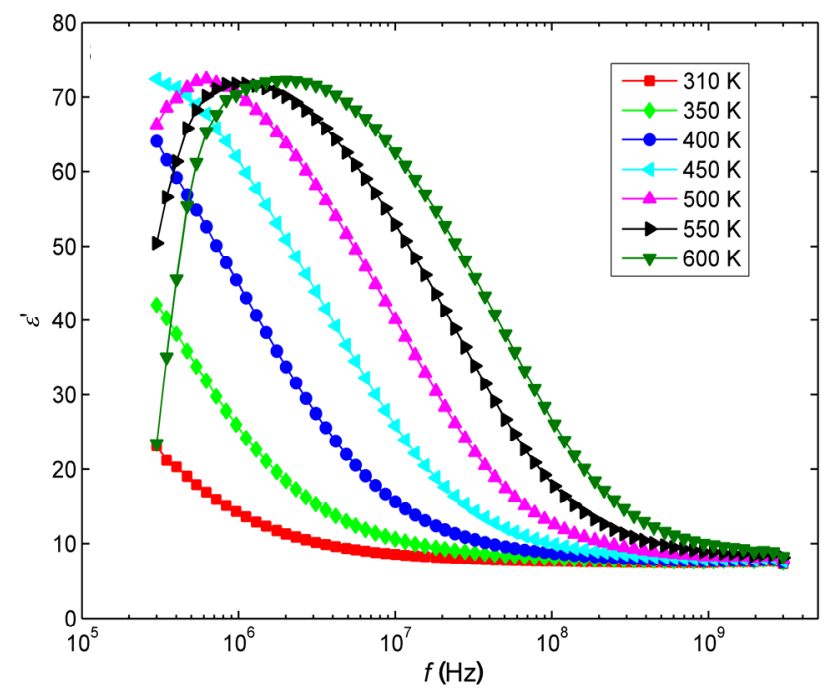

(a)

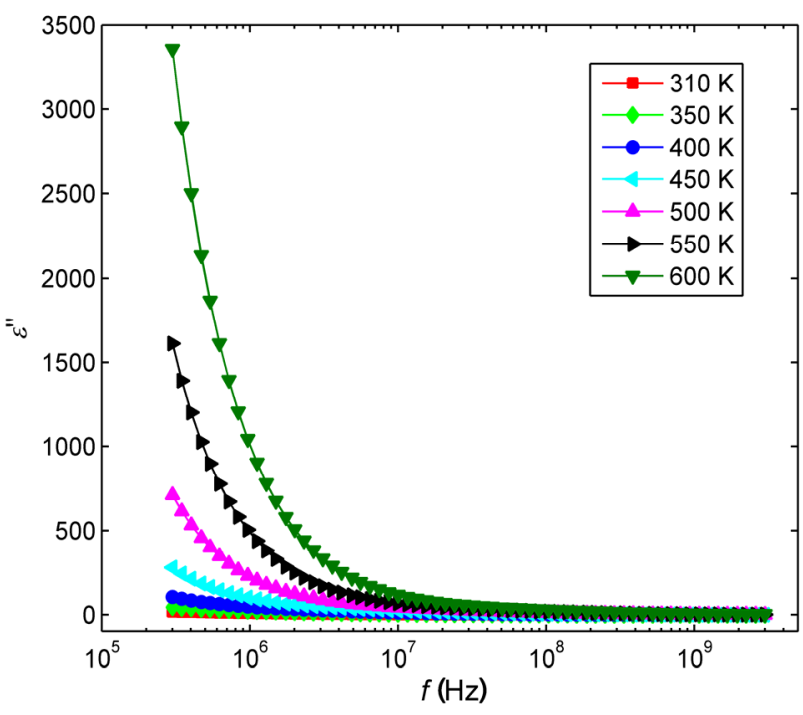

(b) 


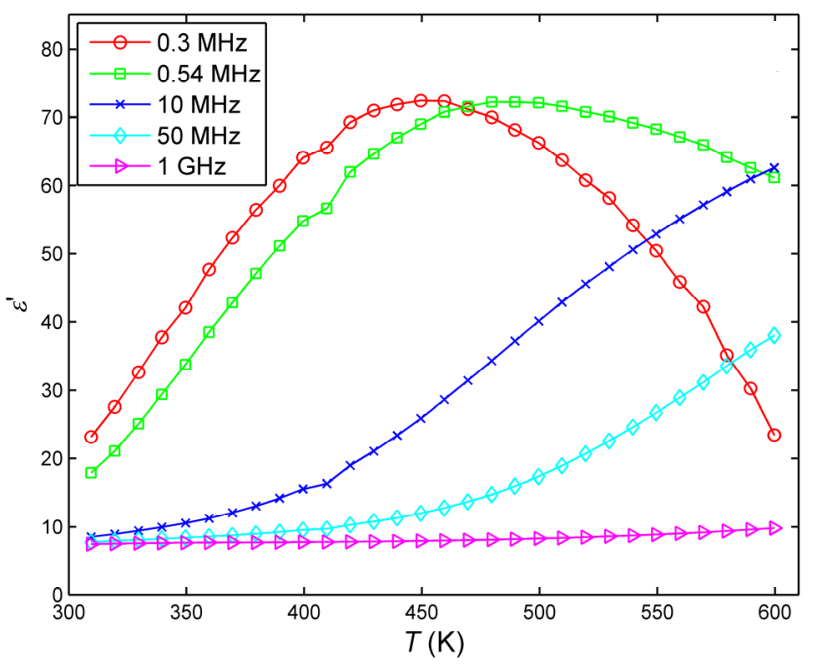

(c)

Figure 9. (a) Plots of real and imaginary parts of dielectric permitivity against frequency at different temperatures for $\mathrm{Na}_{0.5} \mathrm{Li}_{0.5} \mathrm{Zr}_{2}\left(\mathrm{PO}_{4}\right)_{3}$; (b) Imaginary part of dielectric permitivity against frequency at different temperatures for the same composition; (c) Real part of dielectric permitivity against temperature at different frequencies $(0.3 \mathrm{MHz}-1$ GHz).

plots show sharp increase in $\varepsilon^{\prime}$ with increase in temperature, particularly at $0.3-10 \mathrm{MHz}$. At other frequencies $(0.3-0.54 \mathrm{MHz})$ the plots also attain sharp peaks in the value of $\varepsilon^{\prime}$ at $460 \mathrm{~K}$. The increase in $\varepsilon^{\prime}$ leading to the peak can be attributted to interfacial polarization and to the beggining of crystallization [32]. During the crystallization process the interfaces that would be created between the cryststallites with different dielectric constants and conductivities could be the origin of charge accumulation and interfacial polarization. However, the subsequent decrease in the value of $\varepsilon^{\prime}$ above $460 \mathrm{~K}$ is due to reduction of interfacial polarization and low ionic mobility.

\section{Conclusions}

We have used multiple characterization methods (TGA/ DTA, XRD/SEM and IS) for the the purpose of investigating the electrical and dielectric properties of mixed alkali ions $\left(\mathrm{Li}^{+}, \mathrm{Na}^{+}\right)$in the composition $\mathrm{Na}_{0.5} \mathrm{Li}_{0.5} \mathrm{Zr}_{2}$ $\left(\mathrm{PO}_{4}\right)_{3}$. A high value of $\sigma_{b}$ was observed which shows that the conducitvity enhancement was due to higher mobility and polarizability of the mobile ions. The thermal studies showed that there is no significant thermal effects as to affect structural phase change which can affect the conductivity in the temperature and frequency range investigated. A dc conductivity maximum of $0.25 \mathrm{~S} / \mathrm{m}$ was obtained at $580 \mathrm{~K}$ which is within the application range. The variation of the dielectric permitivity showed that the material exhibited dielectric relaxation properties at specific frequencies and temperatures $(450-600 \mathrm{~K})$. Also, peaks were observed in the temperature dependence of the dielectric permitivity around $469 \mathrm{~K}$.

\section{References}

[1] B. Angadi, V. M. Jali, M. T. Lagare, N. S. Kini, A. M. Umarji, R. Kumar, S. K. Arora and D. Kanjilal, "50 MeV $\mathrm{Li}^{3+}$ Irradiation Effects on the Thermal Expansion of $\mathrm{Ca}_{1 \_} \mathrm{Sr}_{\mathrm{x}} \mathrm{Zr}_{4} \mathrm{P}_{6} \mathrm{O}_{24}$," Nuclear Instruments and Methods in Physics Research B, Vol. 187, No. 1, 2002, pp. 87-94. doi:10.1016/S0168-583X(01)00847-3

[2] S. Kormaneni, E. Lenain and R. Roy, "Thermal Expansion of $\mathrm{NH}_{4} \mathrm{Zr}_{2}\left(\mathrm{PO}_{4}\right)_{3}$," Journal of Materials Science Letters, Vol. 5, No. 1, 1986, pp. 1-3. doi:10.1007/BF01671415

[3] I. W. Donald, B. L. Metcalfe and R. N. J. Taylor, "The Immobilization of High Level Radioactive Wastes Using Ceramics and Glasses," Journal of Materials Science, Vol, 32, No. 22, 1997, pp. 5851-5887. doi:10.1023/A:1018646507438

[4] N. Anantharamulu, G. Prasad and M. Vithal, "Preparation, Characterization and Conductivity Studies of $\mathrm{Li}_{3-2 \mathrm{x}} \mathrm{Al}_{2-\mathrm{x}}$ $\mathrm{Sb}_{\mathrm{x}}\left(\mathrm{PO}_{4}\right)_{3}$," Bulletin of Materials Science, Vol. 31, No. 2, 2008, pp.133-138. doi:10.1007/s12034-008-0023-3

[5] T. Salkus, A. Dindune, Z. Kanepe, J. Ronis, A. Kažeonis and A. E. Orliukas, "Synthesis Structure and Electric Properties of $\mathrm{L}_{1+\mathrm{x}} \mathrm{Sc}_{\mathrm{x}} \mathrm{Z}_{2-\mathrm{x}}\left(\mathrm{PO}_{4}\right)_{3}(\mathrm{x}=0.1,0.2,0.3)$," Lithuanian Journal of Physics, Vol. 46, 2006, pp. 361-366. doi:10.3952/lithjphys.46314

[6] H. Kang and N. Cho, "Phase Formation, Sintering Behavior, and Electrical Characteristics of NASICON Compounds," Journal of Materials Science, Vol. 34, No. 20, 1999, pp. 5005-5013. doi:10.1023/A:1004784327302

[7] F. E. Mouahid, M. Zahir, P. M. Maldonado-Manso, S. Bruque, E. R. Losilla, M. A. G. Aranda, A. Rivera, C. Leona and J. Santamaria, "Na-Li Exchange of $\mathrm{Na}_{1+\mathrm{x}} \mathrm{Ti}_{2-\mathrm{x}}$ $\mathrm{Al}_{\mathrm{x}}\left(\mathrm{PO}_{4}\right)_{3}(0.6 \leq x \leq 0.9)$ NASICON Series: A Rietveld and Impedance Study," Journal of Materials Chemistry, Vol. 11, 2001, pp. 3258-3263. doi:10.1039/b102918p

[8] K. Oda, S. Takase and Y. Shimizu, "Preparation of High Conductive Lithium Ceramic," Materials Science Forum, Vol. 544-545, 2007, pp. 1033-1036. doi:10.4028/www.scientific.net/MSF.544-545.1033

[9] P. S. Tantri, K. Greetha, A. M. Umarji and S. K. Ramasesha, "Thermal Expansion Behaviour of Barium and Strontium Zirconium Phosphates," Bulletin of Materials Science, Vol. 23, No. 6, 2000, pp. 491-499. doi:10.1007/BF02903889

[10] V. I. Petkov, A. I. Orlova, I. G. Trucbach, Y. A. Asabina, V. T. Demarin and V. S. Kurazhkovskaya, "Immobilization of Nuclear Waste Materials Containing Different Alkali Elements in Single-Phase NZP-Based Ceramics," Czech Journal of Physics, Vol. 53, No. 1, 2003, pp. A639 -A648. doi:10.1007/s10582-003-0082-Z

[11] A. H. Naik, N. V. Thakkar, S. R. Darwatkar, K. D. S. Mudher and V. V. Venagopal, "Microwave Assisted Low 
Temperature Synthesis of Sodium Zirconium Phosphate $\left(\mathrm{NaZr}_{2}\left(\mathrm{PO}_{4}\right)_{3}\right)$," Journal of Thermal Analysis and Calorimetry, Vol. 76, 2004, pp. 707-713.

[12] A. H. Naik, S. S. Deb, A. B. Chalke, M. K. Saxena, K. L. Ramakumar, V. Venugopal and S. R. Dharwadkar, "Microwave-Assisted Low Temperature Synthesis of Sodium Zirconium Phosphate (NZP) and the Leachability of Some Selected Fission Products Incorporated in Its Structure-A Case Study of Leachability of Caesium," Journal of Chemical Science, Vol. 122, No. 1, 2010, pp. 71-82. doi:10.1007/s12039-010-0009-8

[13] H. Aono, "Studies on $\mathrm{Li}^{+}$Ionic Conducting Solid Electrolyte Composed of Nasicon-Type Structure," Ph.D. Dissertation, Osaka University, Osaka, 1994.

[14] J. Kawamura, N. Kuwata, K. Hattori and J. Misuzaki, "Ionic Transport in Nanohetergenous Materials," Reports of the Institute of Fluid Science, Vol. 19, 2007, pp. 1-2.

[15] J. S. Lee, C. M. Chang, Y. I. Lee, J. H. Lee and S. H. Hong, "Spark Plasma Sintering (SPS) of NASICON Ceramics," Journal of American Ceramic Society, Vol. 87, No. 2, 2004, pp. 305-307. doi:10.1111/j.1551-2916.2004.00305.x

[16] E. Kazakevičius, A. F. Orliukas, A. L. Kežionis, A. L. Jucius, A. Dindune, Z. Kanepe and J. Ronis, "Synthesis and Electrical Properties of $\mathrm{Li}_{1+\mathrm{x}} \mathrm{Zr}_{2-2 \mathrm{x}} \mathrm{Al}_{\mathrm{x}} \mathrm{Ti}_{\mathrm{x}}\left(\mathrm{PO}_{4}\right)_{3}$," Materials Science (Medžiagotyra), Vol. 10, 2004, p. 305.

[17] P. Khatri, B. Behera, V. Srivanus and R. N. P. Choudhary, Complex Impedance Spectroscopic Properties of $\mathrm{Ba}_{3} \mathrm{~V}_{2}$ $\mathrm{O}_{8}$ Ceramics," Research Letters in Materials Science, 2008, p. 3.

[18] C. J. Leo, G. V. S. Rao and B. V. R. Chowdari, "Fast Ion Conduction in the Li-Analogues of Nasicon, $\mathrm{Li}_{1+\mathrm{x}}$ $\left[\left(\mathrm{Ta}_{1-2 \mathrm{x}} \mathrm{Ge}_{\mathrm{x}}\right) \mathrm{Al}\right]\left(\mathrm{PO}_{4}\right)_{3}$," Journal of Materials Chemistry, Vol. 12, No. 6, 2002, pp.1848-1853. doi: $10.1039 / \mathrm{b} 110863 \mathrm{~h}$

[19] D. A. Woodcock, P. Lightfoot and R. I. Smith, "Powder Neutron Diffraction Studies of Three Low Thermal Expansion Phases in the NZP Family: K0.5Nb0.5Ti1.5(PO4)3, Ba0.5Ti2(PO4)3 and Ca0.25Sr0.25-Zr2(PO4)3," Journal of Materials Chemistry, Vol. 9, No. 10, 1999, pp. 2631-2636. doi:10.1039/a903489g

[20] A. Kežionis, E. Kazakevičius, T. Šalkus and A. Orliukas, "Broadband High Frequency Impedance Spectrometer with Working Temperatures up to $1200 \mathrm{~K}$," Solid State Ion, Vol. 188, 2010, pp. 110-113.

[21] V. I. Pet'kov, E. A. Asabina, A. V. Markin and N. N. Smirnova, "Synthesis, Characterization and Thermodynamic Data of Compounds with NZP Structure," Journal of Thermal Analysis and Calorimetry, Vol. 91, 2008, pp.
157-158.

[22] D.-M. Zhu, F. Luo, Z.-L. Xie and W.-C. Zhou, "Phase Formation and Electrical Characteristics of NASICON Ceramics," Transactions of Nonferrous Metal Society of China, Vol. 17, 2007, pp. s1156-s1159.

[23] U. Ahmadu, A. O. Musa, S. A. Jonah and N. Rabiu, "Synthesis and Thermal Characterization of NZP Compounds Na1-xLixZr2(PO4)3 (x=0.00-0.75)," Journal of Thermal Analysis and Calorimetry, Vol. 101, 2010, pp. 175-179. doi:10.1007/s10973-010- 0679-y

[24] C. S. Sunandana and P. S. Kumar, "Theoretical Approaches to Superionic Conductivity," Bulletin of Materials Science, Vol. 27, No. 1, 2004, pp. 1-17. doi:10.1007/BF02708477

[25] J. Bisquert, V. Halpern and F. Henn, "Simple Model for AC Ionic Conduction in Solid," Journal of Chemical Physics, Vol. 122, No. 15, 2005, pp. 151101-1-151101-4. doi:10.1063/1.1896359

[26] A. Gosh, "AC Conduction in Iron Bismuthate Glassy Semiconductors," Physical Review B, Vol. 42, No. 2, 1990, pp. 1388-1393. doi:10.1103/PhysRevB.42.1388

[27] A. Jarboui, A. Ben Rhaeim, F. Hilel, K. Guidara and M. Gargouri, "NMR Study and Electrical Properties Investigation of $\mathrm{Zn}_{2} \mathrm{P}_{2} \mathrm{O}_{7}$," Ionics, Vol. 16, No. 1, 2010, pp. 67 73. doi:10.1007/s11581-009-0333-5

[28] E. E. Shaisha, Sh. F. El-Desouki, I. Shaltout and A. A. Bahgat, "Electrical Relaxation in Mixed Alkali $\mathrm{Bi}_{2} \mathrm{O}_{3}$ $\mathrm{K}_{2} \mathrm{O}-\mathrm{Li}_{2} \mathrm{O}-\mathrm{Fe}_{2} \mathrm{O}_{3}$ Glasses," Journal of Materials Science and Technology, Vol. 22, 2006, pp. 701-707.

[29] I. Vitioo, "Synthesis, Structure, Conductivity and Electrode Properties for Some Double Diphosphates, Silicates and Lithium Manganese Oxides," Ph.D. Dissertation, Institute of Solid State Physics, University of Latvia, Riga, 1999.

[30] Liu J. J., C.-G. Duan, W.-G. Yin, W. N. Mei, R. W. Smith and J. R. Smith, "Dielectric Permittivity and Electric Modulus in $\mathrm{Bi}_{2} \mathrm{Ti}_{4} \mathrm{O}_{11}$," Journal of Chemical Physics, Vol. 119, No. 5, 2003, pp. 2812-2819. doi:10.1063/1.1587685

[31] M. V. N. D. Sharma, A. V. Sarma and R. B. Rao, "Electrical Characterization and Relaxation Behavior of Lithium-Indium-Phosphate Glasses via Impedance Spectroscopy," Turkish Journal of Physics, Vol. 33, 2009, pp. 87-100.

[32] T. R. Choudhary and A. Basu, "Ac Conductivity and Dielectric Relaxation Studies of Sandstone-A Correlation with Its Thermoluminescence," Journal of Ovonic Research, Vol. 4, 2008. pp. 35-42. 